\title{
Vicarious Religion: A Response
}

\author{
Grace Davie \\ University of Exeter, UK
}

It is always pleasing to find one's work as the focus of attention by senior scholars in the field. I am grateful to both Steve Bruce and David Voas for highlighting the notion of "vicarious religion" and for offering their comments on this idea. I am equally grateful to Elisabeth Arweck of the Journal for Contemporary Religion for permitting me to respond to this piece. ${ }^{1}$ My intention in the following paragraphs is two-fold: to clarify what I mean by vicarious religion and to defend my use of this term in the understanding of religion in modern Europe. I will do this under four headings: origins and definition, one factor among many, methodological challenges, and imagination and usage.

One point, however, is important before going further. It concerns the summary that Bruce and Voas give of vicarious religion, which draws largely on my own work (Davie, Religion in Modern Europe and Davie, "Vicarious Religion"). These sources are correct, but the attentive reader would do well to look again at the original texts. In places, the rendering of my account given by Bruce and Voas lacks the nuance that can be seen more easily in the earlier versions.

\section{Origins and definition}

How then did the idea of vicarious religion first emerge? For most of my working life, I have drawn attention to the middle ground in the religious life of both Britain and Europe - i.e. to the very large number of people (around 50\% of the population) who are neither involved with organized religion, nor consciously opposed to it. Both I and others (including Bruce 
and Voas) agree on the importance of doing this. I have also tried to develop tools and concepts which have enabled a better understanding of this constituency. My first attempt to do this led to the phrase "believing without belonging" - an idea which generated a considerable, and continuing debate. Gradually, however, I felt that this phrase needed further refinement, which led in turn to the notion of "vicarious religion". The reasons are as follows.

The separating out of belief from belonging undoubtedly offered fruitful ways in which to understand and to organize the material about religion in modern Europe. Up to a point it also captured the space between the hard and soft variables concerning religious attachments: belief normally gathers a wider constituency than belonging. On-going reflection about the current situation, however, has encouraged me to reflect more deeply about the relationship between the belief and belonging. It is quite clear, for example, that "belief" can be both hard and soft, as indeed can "belonging". It was in thinking about the latter, that the notion of vicarious religion began to emerge. It was a way of describing the continuing attachment of large sections of the European population to their historic churches, whether or not they attended these institutions on a regular basis. I came to the conclusionfor the reasons set out in the two articles listed above - that the idea of vicarious religion, as "the notion of religion performed by an active minority but on behalf of a much larger number, who (implicitly at least) not only understand, but, quite clearly, approve of what the minority is doing” ("Vicarious Religion" 22) was a helpful contribution to the sociological debate.

Large numbers of people (scholars, journalists, practitioners, commentators of various kinds) agree with me. But not everyone is equally positive, including Bruce and Voas. It is unwise to generalize, but on the whole those who resist the idea of vicarious religion fall into the same category as those who resist the notion of believing without belonging, and for the 
same reasons. All of them do a similar thing. They take a concept that was intended to direct attention to the religious habits of a section of the population that remains loosely attached to the mainstream churches of Europe (and to find creative ways of thinking about their behaviour), and turn this into something far more rigorously defined that I intended. The next step is to "test" this reconfigured notion in a way that is not appropriate. Precisely this has happened in the preceding article. If "vicarious religion" is defined in the way that these authors prefer, then the logic of their argument is clear enough - but the phrase was never intended to be used in this way. It is for this reason that the essential subtlety is lost.

And whatever the case, the underlying problem remains: how do we understand the religious penumbra of modern European societies and how should we describe this sociologically? Voas offers "fuzzy fidelity" as an alternative (Voas). I have absolutely no problem with the latter, but remain convinced that a notion that probes the implicit and well as explicit connections between this still significant body of people and the historic churches of Europe remains a useful contribution.

\section{One factor among many}

A second point is equally important - the notion of vicarious religion needs to be placed in context. It is not the only variable to be taken into account. There are, in fact, five or six factors that must be considered if we are to grasp fully the complexities of the current situation with regard to religion in Europe (see Davie, "Is Europe the exceptional case?", and "Religion in Europe in the $21^{\text {st }}$ century"). These factors not only change and adapt over time, they push and pull in different directions. The six factors are:

1. The role of the historic churches in shaping European culture. This is easily illustrated in the sense that the Christian tradition has had an irreversible effect on time (calendars, 
seasons, festivals, holidays, weeks and weekends) and space (the parish system and the dominance of Christian buildings) in this part of the world.

2. An awareness that the historic churches still have a place at particular moments in the lives of modern Europeans, though they are no longer able to discipline the beliefs and behaviour of the great majority of the population. Despite their relatively secularity, Europeans are likely to return to their churches at moments of celebration or grief (whether individual or collective).

3. An observable change in the churchgoing constituencies of the continent, which operate increasingly on a model of choice, rather than a model of obligation or duty. As a result, membership of the historic churches is changing in nature; increasingly it is chosen rather than inherited, though more so in some places than in others.

4. The arrival into Europe of groups of people from many different parts of the world. This is primarily an economic movement, but the implications for the religious life of the continent are immense. The growing presence of Christians from the global South alongside significant other faith communities has altered the religious profile of Europe. Quite apart from this, some of these communities are - simply by their presence challenging some deeply held European assumptions, notably the notion that religion should be considered a private matter.

5. Rather different are the sometimes vehement reactions of Europe's secular elites to this shift: i.e. to the increasing significance of religion in public as well as private life. Such elites did not anticipate a change of this nature and have been obliged to respond, sometimes aggressively, sometimes less so.

6. A gradual, but growing realization that the patterns of religious life in modern Europe should be considered an 'exceptional case' - they are not a global prototype. It short, Europeans are beginning to realize that Europe is secular not because it is modern, but 
because it is European. It is equally true that some Europeans welcome this insight; others are disconcerted by it.

Vicarious religion is easily located in this list - it is one way of understanding better the implications of the second factor: the awareness that the historic churches still have a place at particular moments in the lives of modern Europeans, though they are no longer able to discipline the beliefs and behaviour of the great majority of the population. "Believing without belonging", the predecessor of vicarious religion can be similarly placed. Neither, however, is the whole story, nor was it ever intended to be. Indeed a number of Bruce's and Voas' criticisms can be answered by taking some of the other factors into account - notably the first (cultural heritage) and the third (the shift from obligation to consumption). It is simply that they have selected one factor for their attention and found it incapable of explaining everything. I agree.

An additional point follows from this. In both the articles cited in this section, I argue that vicarious religion is a crucial factor in understanding religion in Europe at the present moment. I also state quite clearly that I do not expect this idea to resonate indefinitely. Specifically, I suggest that by the mid twenty-first century, something rather different will be happening: increasingly religion will be chosen rather than inherited and the range of choices will include forms of religion that have come into Europe from outside. Vicarious religious is not, therefore, the opposite of secularization theory, as Bruce and Voas seem to imply; it is one factor among many in the continuing re-adjustments of religious life in modern Europe. Interestingly, Voas suggests the same with respect to fuzzy fidelity - that is will rise and fall over a very extended period. How long that will take is an empirical question; it cannot be assumed at the outset. 


\section{Methodological challenges}

For the time being, therefore, vicarious religion requires our close attention, which presents in turn a significant methodological challenge. This was one reason for the illustrations of this concept set out in Davie ("Vicarious Religion"): how does it work in practice? There is no need to repeat these here, though to appreciate their subtlety, they do need to be read in the original rather than in the Bruce and Voas version. All of them have one thing in common: they are attempts to reveal forms of religion that normally lie hidden. An iceberg may provide a helpful analogy. It is easy enough both to measure and to take note of the part of the iceberg that emerges from the water. But this is to ignore the mass underneath, which is invisible for most of the time - but without which the visible part would not be there at all. How, though, can a sociologist penetrate more deeply in order to understand what is going on beneath the surface?

One way is to observe societies at particular moments in their evolution when "normal" ways of living, for one reason or another, are suspended and something far more instinctive comes to the fore. As Bruce and Voas note, I have used the examples of Princess Diana and of the tragic episode that took place in village of Soham, Cambridgeshire, in 2004 to illustrate this point. My interlocutors choose to interpret these events rather differently. To be frank, I do not accept their readings of these episodes, nor the tone in which they are delivered, but that in turn depends on how you define vicarious religion in the first place - we are in danger of going round in circles. It might be more helpful to try another example. Without doubt, the unexpected and very poignant series of actions that took place at the end of Jade Goody's life offer an almost perfect example of what I am trying to convey (whatever you choose to call it). Here is a young woman whose life-style was a million miles from the respectabilities of traditional Anglicanism. At the end of her short life, however, she turned to the church repeatedly - for the baptism of her children and for herself, for her somewhat 
unusual wedding, and finally for her much more traditional funeral. Please don't tell me that the priest who enabled all this was merely the best person to act as "master of ceremonies" on these very affecting occasions. Something rather more profound was going on which demands our sociological attention. Further very penetrating examples can be found in Coakley and Wells. It is episodes such as these that I doing my best to understand.

The crucial point to grasp in terms of sociological method is the need to be attentive to moments, whether individual or collective, in or through which the implicit becomes explicit. It is equally important to remember that the examples described above are simply large-scale and often media-hyped versions of what goes on all the time in the life-cycles of ordinary people. Individual families and communities regularly pause for thought at critical moments in their existence, frequently marking these with some form of liturgy (Billings). These are moments when the normal routines of life are suspended, when - to put the same point in a different way - the abnormal becomes normal, in terms of conversation as well as behaviour. You need only listen to the conversation immediately after a birth or a death to realize that.

What in fact is at stake in these debates is a philosophy of science which has profound implications for methodology. Social life is not merely an aggregate of individual attitudes and behaviours, and thus amenable to the survey research so beloved of positivists. It is a subtle, many-layered, shifting and constantly evolving entity, which cannot easily be broken down into straightforward, testable hypotheses. Vicarious religious must be approached accordingly. It involves not only individuals, but institutions, traditions, assumptions, emotions, dispositions - including unconscious ones; it requires therefore an historically informed, highly sophisticated research design to test it adequately. How this is done may vary from place to place, but above all it calls for a developed sociological imagination. 


\section{Imagination and usage}

Who better than C.W. Mills to evoke the sociological imagination? Not himself interested in religion, he suggests nonetheless that we "re-arrange" the file, abandon the conventional script, engage with reality rather than received truth, but - at the same time - think rigorously about what is going on (Mills). In short, the aim of social science is to open up new areas of research, to pose new research questions and to investigate them thoroughly. How then should we approach the sections of the population who are neither involved with organized religion, nor consciously opposed to it and what are the precise research questions which might stimulate the debate? Might not careful and, above all, sensitive thinking about the notion of vicarious religion be one way of doing this?

Rather more pragmatically, I rest my case for the helpfulness of this concept on my own experience. I have introduced this idea all over Europe (from the Nordic countries to the Balkans), and in virtually every situation it is not only understood by the audience in question but evokes a positive response, together with a host of examples from whatever context I am in. The fact that this happens repeatedly despite language differences and the need to work with an interpreter is remarkable. Indeed the reactions of interpreters are interesting in themselves: at first somewhat baffled (this is not a common place term for most of them), they get the idea very quickly and find ways of expressing it in their own language. The response is invariably gratifying.

In the United States, conversely, where the religious situation is very different, even an English-speaking audience finds it difficult to grasp this idea - quite clearly it does not resonate with American self-understanding. Indeed vicarious religion captures the contrast between the patterns of religion in Europe and the United States almost better than anything else - Bellah's "civil religion" is close, but it is not the same. The essential difference lies in the "on behalf of" element in vicarious religion, which rests in turn on the legacy of the state 
church. Mentalities endure even when the institution has altered considerably. Here then is yet another reason to appreciate the usefulness of vicarious religion. Not only does it help us to penetrate the middle ground of religious life in Europe, it also highlights the specificity of the European case.

The clearest illustrations of all can, of course, be found in those parts of Europe (the Nordic countries and Germany) where some form of church tax is still in place - in other words where the population as a whole, rather than the actively faithful, contribute to the maintenance of the churches and to the people who work in them. The most striking thing about the Nordic countries is the relatively small number of people who decide to "contract out" of this system. Some do, but most continue tangibly to support their churches (the financial contribution is not negligible), despite the markedly low levels of both churchgoing and orthodox religious belief in this part of the world. Why do they do this? One assumes that they wish these institutions to continue in existence.

The German case, conversely, is changing rapidly, provoked at least in part by the different religious situation in the former East - reminding us that vicarious religion is more vulnerable in some parts of Europe than others. Particularly in the Protestant churches of Germany, membership (together with financial contributions) is falling fast. Interestingly, however, it is German scholars - notably Jürgen Habermas - who have prompted the next stage in my thinking. Appreciative of the concept of vicarious religious, they have asked a different, more philosophical question. Does the notion of acting vicariously imply intentionality? Is it necessary, in other words, for the actor to be conscious of what he or she is doing? And how might this apply to institutions? Encouraged by their attention to my work, I continue to reflect on the implications of these insights. I have no doubt that the debate will continue. 


\section{References}

Billings, A. Secular Lives, Sacred Hearts. London: SPCK, 2004.

Coakley, S. and S. Wells (eds). Praying for England. London: Continuum, 2008.

Davie, G. Religion in Modern Europe: A Memory Mutates. Oxford: Oxford University Press, 2000.

---. "Vicarious Religion: A Methodological Challenge.” Ed. N.T. Ammerman. Everyday Religion: Observing Modern Religious Lives. New York: Oxford University Press, 2006. 21 35 .

---. “Is Europe an Exceptional Case?” The Hedgehog Review, 8/1-2 (2006): 23-35.

---. "Religion in Europe in the $21^{\text {st }}$ Century: The Factors to Take into Account." Archives européennes de sociologie/ European Journal of Sociology/ Europaeisches Archiv für Soziologie, XLVII, 2006: 271-96.

Mills, C.W. The Sociological Imagination. Oxford University Press, 2000 (first published 1959).

Voas, D. "The Rise and Fall of Fuzzy Fidelity in Europe." European Sociological Review, (2009), 25/2: 155-168. 
${ }^{1}$ Warm thanks are also due to the various scholars who have helped me to understand better the notion of vicarious religion - among them are Nancy Ammerman, Peter Berger, David Martin and Linda Woodhead, some of whom have offered valuable comments on this response. 